\title{
JIMMBA
}

\section{Pengaruh Tax Avoidance Terhadap Struktur Modal dengan Return on Asset sebagai Variabel Mediasi}

\author{
Leader Joy Lumbanraja ${ }^{1}$, Francis Hutabarat ${ }^{2}$
}

1,2Universitas Advent Indonesia

Email: leaderjoylumbanraja@gmail.com¹,fmhutabarat@unai.edu²

\begin{tabular}{|c|c|}
\hline ARTICLE INFO & ABSTRACT \\
\hline $\begin{array}{l}\text { Article History: } \\
\text { Received: September } 30^{\text {th }} \\
2020 \\
\text { Accepted: October } 23^{\text {rd }} 2020 \\
\text { Published: December } 1^{\text {st }} 2020 \\
\text { Keywords: } \\
\text { Tax Avoidance, Capital } \\
\text { Structure, Return on Asset }\end{array}$ & $\begin{array}{l}\text { The purpose of this study was to examine and analyze the effect of } \\
\text { tax avoidance on capital structure with the mediating variable return } \\
\text { on assets (ROA) in construction sub-sector companies on the } \\
\text { Indonesia Stock Exchange in 2018-2019. This research uses } \\
\text { quantitative methods. The research data is in the form of secondary } \\
\text { data taken from the annual financial reports of } 11 \text { construction sub- } \\
\text { sector companies. Research variables are tax avoidance (X1), return } \\
\text { on assets / ROA (X2) and capital structure (Y). The data analysis } \\
\text { method used is path analysis. The test results prove that Tax } \\
\text { Avoidance and Capital Structure have a significant effect, return on } \\
\text { assets and Capital Structure have a significant effect, and Tax } \\
\text { Avoidance on Capital Structure with return on assets as a mediating } \\
\text { variable has a significant effect. }\end{array}$ \\
\hline
\end{tabular}

\section{Pendahuluan}

Perusahaan merupan suatu perkumpulan individu maupun organisasi yang mempunyai pencapaian yang serupa, yakni untuk meraih profit dari aktivitas yang dilakukan oleh perusahaan. Ada berbagai jenis perusahaan di indonesia seperti perusahan dagang, perusahaan jasa, dan perusahaan industi. Setiap perusahaan memiliki daya saing yang kuat agar memperoleh profit yang tinggi. Salah satu perusahaan jasa konstruksi, perusahaan konstruksi merupakan suatu pekerjaan yang membangun.

Berdirinya perusahaan yang ada di indonesia tentunya memiliki tujuan yang berlain-lainan. Namun selaku harafiah nya, perusahaan bukan semata mata diminta untuk mendapatkan keuntungan yang sebanyak-banyaknya. Namun perusahaan pula diminta sanggup mengembangkan nilai perusahaan dan mensejahterakan sumber daya manusia dalam perusahaan. Untuk mewujudkan nya, perusahaan membuat produk produk yang berkualitas disertai dengan modal yang maksimal.

Suatu kejadian yang tidak mampu di hindari dalam dunia pasar saat ini yaitu lahirnya rasa rivalitas didalam tubuh perusahaan maupun perusahaan lain. Dengan cara membuat produk dari setiap perusahaan itu sendiri agar mampu bersaing dalam dunia pemasaran, baik dalam 
Negara sendiri ataupun di Negara luar. Demi menjalankan bisnis setiap perusahaan membutuhkan modal. Sumber dana yang dimiliki perusahaan yaitu dari hutang maupun dari pemilik perusahaan itu sendiri. Husnan (2002) menyatakan bahwa struktur modal menggambarkan perimbangan antara dana sendiri dengan kewajiban pada laporan keuangan diperusahaan.

Didalam laporan keuangan perusahaan Masalah penting yang sering kali dihadapi perusahaan yaitu masalah struktur modal, sehingga baik atau tidaknya modal perusahaan akan mempengaruhi laba dalam laporan keuangan perusahaan tersebut. Sartono (2001) struktur modal yang tidak baik dapat memberikan pengaruh biaya tetap yang mencakup biaya modal yang tinggi akan mempengaruhi pada laba yang diperoleh pada perusahaan. Suatu perusahaan dinamakan memiliki struktur modal nan baik, dimana memiliki laba nan tinggi dibandingkan hutang. Untuk menjaga struktur modal yang baik dengan cara pengurangan pajak dan pengembalian asset.

Dengan demikian peneliti mengambil kasus yang ditulis Prasetyo (2019) yang tercantum di situs beritasatu.com yang berjudul Perkuat Struktur Modal, Bank Mayapada Tidak Bagi Dividen, dimana bank mayapada menahan dividen untuk memperkuat struktur pemodalan karena bank ini mengalami kerugian 35,24\% turun di bandingkan tahun sebelumnya.ditahun 2018 bank mayapada membukukan laba bersih sebesar Rp437,405 sedangkan ditahun 2017 Rp 675,405 dikarenakan kerugian ini sehingga rapat umum pemegang saham dari bank mayapada mengganti direksi hariati tupang dengan yang baru yaitu freddy soejandy untuk direktur perseroan. Dengan demikian sangat menarik untuk mengupas bagaimana mediasi dari variabel return on asset berpengaruh pada hubungan tax avoidance dan struktur modal pada perusahaan kontruksi tahun 2018-2019 yang tercantum pada Bursa Efek Indonesia.

\section{Kajian Teori dan Telaah Literatur}

\section{Tax Avoidance}

Tax avoidance merupakan suatu cara dari perusahaan dapat menghindari pajak dengan ilegal yang sama sekali tidak melawan hukum perpajakan sama sekali. Menurut Priantara (2011) Tax avoidance merupakan upaya-upaya yang masih termasuk di dalam konteks peraturanperaturan pajak nan masih berjalan dengan menggunakan celah hukum untuk meminimalkan nilai pajak yang tertunggak dari tahun sekarang dan tahun-tahun yang akan datang.

Return on asset. Meskipun pada umum nya pengelakan pajak merupakan langkah yang tabiatnya mengecilkan tunggakan pajak dan bukan memperkecil kesanggupan atau menyelesaikan kewajiban kewajiban nya oleh wajib pajak, dalam kondisi ini hendaknya perusahaan mengusahakan agar tidak terjebak didalam perbuatan yang disangka sebagai pekerjaan penyeludupan pajak (Tarihoran, 2016).

Tax avoidance juga yang disebut sebagai tax planning adalah tindakan cermat yang dibuat dalam pengendalian tindakan supaya tidak terkena dari pengenaan pajak yang konsekuensi tidak dikehendaki.penghindaran pajak merupakan tindakan pengiritan pajak yang masih dalam ruang lingkup perundang-undangan (lawful fashion) (Ilmiani \& Sutrisno, 2014).

Lim (2010) mengemukakan bahwa tax avoidance sebagai pengiritantan pajak yang muncul dengan memanfaatkan ketetapan perpajakan yang dilakukan secara valid untuk memperkecil kewajiban. Dyreng, et al. (2008) mendefenisikan bahwa penghindaran pajak yakni seluruh 
bentuk aktivitas yang memberikan pengaruh terhadap kewajiban pajak, baik kegiatan yang diizinkan oleh pajak maupun aktivitas khusus agar memperkecil pajak.

\section{Return on Asset}

Sering juga disebut sebagai salah satu cara untuk menunjukkan persentase keuntungan bersih yang di dapat perusahaan dengan rata rata aset atau keseluruhan sumberdaya. Maksud nya ialah ROA merupakan tolak ukur sebaik apakah suatu perusahaan mengurus penghasilan selama satu periode. Marfuatun dan Indarti (2012) menyatakan bahwa Return on Asset (ROA) memberikan gambaran seberapa efektif suatu perusahaan dalam melakukan tindakan usahanya, dimana perbandingan ini mengenali seberapa banyak profit nan mampu diperoleh pada umumnya terhadap setiap rupiah asetnya. Variabel Independen dalam penelitian ini penghindaran pajak. penghitungan Tax Avoidance memakai Cash Effective Tax Rate (CETR). dengan rumus sebagai berikut:

$$
\text { CETR }=\frac{\text { Pembayaran pajak }}{\text { Laba sebelum pajak }}
$$

Semakin kecil Cash ETR menandakan semakin tinggi tingkat penghindaran pajak perusahaan sebliknya semakin besar Cash ETR menandakan semakin rendah tingkat penghindaran pajak perusahaan. Sebaliknya (Budiman \& Setiyono, 2012).

\section{Struktur Modal}

Salah satu pencapaian yang terpenting dalam sebuah perusahaan adalah memajukan kualitas perusahaan. Pada umumnya untuk memperoleh pencapaian ini perusahaan dapat mempelajari tekstur struktur modalnya. Melambungnya taraf perusahaan diharapkan juga mampu mensejahterakan dan meningkatkan kemakmuran pemegang saham. Tingkat pengembangan usaha yang besar akan membutuhkan sumber dana yang besar didalam perusahaan, sebagai upaya untuk menambahkan kebutuhan dana dalam proses pengembangan usaha tersebut sehingga dibutuhkan tambahan dana segar dari pihak eksternal (Dhani \& Utama, 2017).

Hermuningsih (2012) menyatakan bahwa struktur modal menjadi sentral perbaikan daya cipta dan kemampuan perusahaan. Teori struktur modal menjelaskan bahwa financial policy (kebijakan pendanaan) perusahaan dalam menentukan struktur modal (bauran antara hutang dan ekuitas) memiliki tujuan untuk mengoptimalkan nilai perusahaan.Dewi et al., (2014) mengemukakan calon investor bisa menggunakan Debt to Asset Ratio sebagai pandangan mereka untuk berinvestasi ke dalam perusahaan karena memaparkan total aset yang dapat menggambarkan tingkat pengembalian yang akan diperoleh perusahaan. Sehingga perusahaan mampu memahami pada level mana dianggap aman untuk peminjaman. Maksimal peminjaman itu ialah $40 \%$ dari jumlah nilai asset ini merupakan titik aman dari peminjaman dengan rumus:

$$
\text { DAR }=\frac{\text { Total Utang }}{\text { Total Aset }}
$$




\section{Tax Avoidance dan Struktur Modal}

Tax avoidance merupakan cara yang dilakukan oleh perusahaan agar dapat menghindari pengenaan pajak yang tidak di ingin kan oleh perusahaan, penghindaran pajak dapat juga dikatakan sebagai penghematan pajak yang tidak melanggar undang undang.

Penelitian yang dilakukan sebelum nya oleh Pratana P. Midiastuty dkk. (2017) Perusahaan yang tidak melakukan usaha penghindaran pajak mempunyai pengaruh yang lebih kecil terhadap struktur modal dari pada perusahaan yang melakukan penghindaran pajak. Sedangkan menurut Rudi, Susi Dwimulyani (2019) penghindaran pajak tidak memiliki pengaruh yang signifikan. Pemakaian hutang dapat digantikan berupa Penghindaran pajak (tax avoidance) berartian bahwa dalam penghindaran pajak boleh menjadi pengganti dari pemakaian hutang pajak perusahaan menjadi tinggi dikarenakan dimana saat perusahaan tidak menggunakan hutang dalam pendanaannya. Ditemukan pengaruh yang signifikan dari Hubungan antara ETR dan Stuktur Modal. Hasil penelitian (Widyaningrum, 2015) menyatakan Tax avoidance mempunyai pengaruh positif terhadap stuktur modal tetapi, menurut penelitian (Pratheepan dan Banda 2016) bahwa tax avoidance berpengaruh negatif terhdap stuktur modal.

$\mathbf{H}_{\mathbf{1}}$ : Tax Avoidance berpengaruh terhadap Struktur modal

\section{Return on Asset berpengaruh terhadap Struktur Modal}

ROA merupakan cara menilai kesanggupan perusahaan dalam memperoleh laba dengan menggunakan total asset perusahaan yang dimilikinya setelah diselaraskan dengan bebanbeban untuk membiayai aset tersebut. Faktor-Faktor dalam Memengaruhi Struktur Modal ialah; Managerial Ownership, Pertumbuhan Penjualan,dan Return on Asset (ROA). Lazimnya dalam mengukur kemampuan suatu perusahaan digunakan analisis daya laba (ROA) memperhatikankan kecakapan perusahaan dalam memperoleh earning pada kegiatan perusahaan.

Penelitian yang dilakukan sebelumnya atau penelitian terdahulu yang dilakukan oleh Karadeniz, et al ( 2009) menyatakan ROA dan struktur modal tidak ada hubungan positif. Menurut Wiwit Apit Sulistyowati (2008) profitabilitas (ROA) dengan struktur modal berhubungan negatif. Candra Sekhar Mishra (2011) didapat kesimpulan bahwa ROA dan struktur modal berhubungan negatif. Menurut Seftianne dan Ratih Handayani (2011) didapat kesimpulan bahwa profitabilitas (ROA) tidak berpengaruh terhadap struktur modal.,dan Wardani (2015), menyatakan ROA terhadap struktur modal tidak berpengaruh signifikan.

Namun penelitian yang dilakukan Teker, Tasseven, dan Tukel (2009) didapatkan hasil bahwa ROA dan struktur modal berhubungan positif dan signifikan. tingkat perputaran Debt to Asset Ratio berpengaruh positif terhadap Return on Asset. (Dewa Kadek Oka Kusumajaya.2011).

$\mathbf{H}_{2}$ : Return on asset berpengaruh terhadap struktur modal 


\section{Model Penelitian}

Pada penelitian ini di dapati ada dua variable yang di miliki, yaitu variable terkait $(\mathrm{Y})$ yaitu struktur modal (DAR) yang dipengaruhi oleh variable $(X)$ sebagai variable bebas, yaitu tax avoidance Atau Effective tax rate (ETR) dan sebagai variable mediasinya ialah Return on asset (ROA)

\section{Populasi dan Sampel}

Sugiyono (2006) mengatakan bahwa populasi merupakan suatu subjek yang di digunakan untuk mengambil sampel yang memiliki kualitas dan kuantitas tertentu yang di gunakan dalam karya ilmiah sebagai pelajaran dan akhirnya dapat memperoleh kesimpulan Peneliti menggunakan perusahaan terdatar di Bursa Efek Indonesia sebagai populasi. Namun peneliti tidak menggunakan semua semua populasi hanya pada bagian sub sektor kontruksi saja. Yang tertera di BEI adalah sebanyak 11 perusahaan pada tahun 2019-2018 ini lah yang menjadi populasi penelitian, dan datanya sebanyak 22 yang dibuat menjadi sample.

\section{Sumber data}

Data sekunder ialah data yang di dapat dari pihak lain yang menyediakan laporan keuangan seperti halnya BEI dan bukan di peroleh langsung dari sumbernya (Wahyuni 2009). Data sekunder digunakan dalam karya ilmiah berikut ini. Peneliti menggunakan data pada tahun 2019-2018 untuk diolah.

\section{Analisis data}

Data yang terkumpul dikelola dengan menggunakan perangkat lunak SPSS yang digunakan sebagai alat dalam pengolahan data. Teknis analisis regresi linear berganda digunakan dalam peneltian ini. Untuk menguji pengaruh antara veriable $X$ terhadap variable $Y$ dengan simultas, sehingga digunakanlah Uji $F$. Sedangkan dalan memeriksa pengaruh antara variable $X$ terhadap variabel $Y$ dengan cara parsial maka digunakan uji t. Setelah hasil uji asumsi klasik diperoleh semuanya, langkah berikutnyanya menetapkan R2 atau koefisian determinasi dan uji $\mathrm{F}$ beserta uji $\mathrm{t}$ sebagai pengembangan dan sebagai berikut merupakan dasar dalam pengujian data regresi linear berganda.

\section{Hasil dan Pembahasan}

\section{Uji-F}

Tabel 1. Hasil uji-F

\begin{tabular}{|c|c|c|c|c|c|c|}
\hline Model & & $\begin{array}{l}\text { Sum of } \\
\text { Squares }\end{array}$ & Df & Mean Square & $\mathrm{F}$ & Sig. \\
\hline \multirow[t]{3}{*}{1} & Regression & 161451.507 & 1 & 161451.507 & .289 & $.597^{a}$ \\
\hline & Residual & $1.116 \mathrm{E} 7$ & 20 & 557836.810 & & \\
\hline & Total & $1.132 \mathrm{E} 7$ & 21 & & & \\
\hline \multirow[t]{3}{*}{2} & Regression & 4270604.357 & 2 & 2135302.179 & 5.757 & $.011^{\mathrm{b}}$ \\
\hline & Residual & 7047583.351 & 19 & 370925.440 & & \\
\hline & Total & $1.132 \mathrm{E} 7$ & 21 & & & \\
\hline
\end{tabular}

Sumber: Data sekunder diolah 
Hasil uji signifikan menunjukkan bahwa pada model 1 bahwa antara ETR terhadap struktur modal tidak ada pengaruh yang signifikan. Hal ini dapat dilihat dari nilai F-test .289 dan nilai significant 0.597 pada $\alpha=0.05$ atau 5\%. Sedangkan pada model 2, didapati bahwa dengan adanya mediasi ROA maka didapati pengaruh ETR, ROA terhadap struktur modal adalah significant dengan tingkat signifikan 0.011 pada $\alpha=0.05$ atau $5 \%$ dengan F-test 5.757 .

\section{Uji-t}

Tabel 2. Hasil Uji-t

\begin{tabular}{|c|c|c|c|c|c|c|}
\hline \multirow[b]{2}{*}{ Model } & & \multicolumn{2}{|c|}{ Unstandardized Coefficients } & \multirow{2}{*}{$\begin{array}{c}\text { Standardized } \\
\text { Coefficients }\end{array}$} & \multirow[b]{2}{*}{$\mathrm{t}$} & \multirow[b]{2}{*}{ Sig. } \\
\hline & & B & Std. Error & & & \\
\hline \multirow[t]{2}{*}{1} & (Constant) & 331.017 & 172.978 & & 1.914 & .070 \\
\hline & ETR & -213.293 & 396.469 & -.119 & -.538 & .597 \\
\hline \multirow[t]{3}{*}{2} & (Constant) & 585.867 & 160.494 & & 3.650 & .002 \\
\hline & ETR & -277.938 & 323.878 & -.156 & -.858 & .402 \\
\hline & ROA & -84.570 & 25.409 & -.604 & -3.328 & .004 \\
\hline
\end{tabular}

Sumber: Data sekunder diolah

Hasil uji signifikan menunjukkan bahwa diantara variable independent maka terlihat bahwa pada model 1 tidak ada pengaruh signifikan pada variable ETR terhadap struktur modal dengan nilai signifikan 0.597 pada level signifikan 5\%. Sedangkan pada model 2, didapati dengan adanya mediasi ROA, didapati bahwa ETR dan struktur modal tetap memiliki pengaruh yang tidak signifikan yaitu 0.402 pada level signifikan 5\%. Dan terkait ROA dan Struktur modal didapati adanya pengaruh yang signifikan dengan level signifikan 0.004 pada level signifikan 5\%. Dengan demikian keberadaan ROE sepenuhnya memediasi pengaruh ETR dan struktur modal. Adapun model regresi yang didapat adalah:

$$
\begin{aligned}
& \mathrm{DER}_{1}=331.017-213.293 \mathrm{ETR}_{1} \\
& \mathrm{DER}_{2}=585.867-277.938 \mathrm{ETR}_{2}-84.570 \mathrm{ROE}_{2}
\end{aligned}
$$

\section{Uji Koefisien Determinasi}

\begin{tabular}{|c|c|c|c|c|}
\hline Model & $\mathrm{R}$ & $\mathrm{R} \mathrm{Sq}$ & R Sq Chg & $\begin{array}{l}\text { Std. Err of the } \\
\text { Estimate }\end{array}$ \\
\hline 1 & $.119 a$ & .014 & .014 & 746.88474 \\
\hline 2 & $.614^{\mathrm{b}}$ & .377 & .377 & 609.03648 \\
\hline
\end{tabular}

Tabel 3. Hasil Uji Koefisien Determinasi

Sumber: Data sekunder diolah

Tabel diatas menggambarkan bahwa pada model 1 nilai R-Square adalah sebesar .014 yang berarti kontribusi ETR terhadap perubahan pada struktur modal adalah sebesar $1.4 \%$. Terkait model 2, didapati bahwa dengan mediasi ROA maka didapati kontribusi ETR dan ROA terhadap perubahan pada struktur modal menjadi sebesar $37.7 \%$ dan didapati perubahan dalam nilai R-Square change sebesar 0.363 atau $36.3 \%$. 


\section{Pembahasan}

Pada penelitian ini didapati bahwa hipotesa 1 antara ETR dan Struktur Modal memiliki pernyataan bahwa terdapat pengaruh yang signifikan. ETR merupakan rasio tingkat pembayaran pajak perusahaan. Berdasarkan hasil uji mengatakan bahwa antara ETR dan Struktur Modal tidak ada pengaruh yang signifikan. Hasil penelitian (Wijayanti, Samrotun, dan Mulatsari, 2020); (Kusufiyah dan Anggraini, 2018); (Kim dan Zhang, 2011) Tax Avoidance terhadap struktur modal mempunyai pengaruh positif. Dan menurut penelitian (Panggabean, 2018); (Varventy, 2017); (Kristianto, Andini, dan Santos, 2018) tax avoidance berpengaruh significant negatif terhadap struktur modal.

Pada penelitian ini didapati bahwa hipotesa 2 antara ROA dan Struktur Modal memiliki pernyataan bahwa terdapat pengaruh yang signifikan. ROA merupakan skala yang menghitung tingkat keuntungan perusahaan berdasarkan asset perusahaan. Berdasarkan hasil uji mengatakan bahwa antara ROA dan Struktur Modal ada pengaruh yang signifikan pada model 2 untuk level signifikan 5\%. Hasil penelitian (Hasanah dan Ainni, 2019); (Sabrina, dan Lestari, 2020); (Zahroh, Rahayu, dan Azhari, 2016); (Anbar dan Alper, 2011); (Nababan, 2019) Return on Asset memiliki pengaruh positif yang significant pada Struktur Modal. Sedangkan hasil penelitian (Sainan, Philip, Manullang, dan Halim, 2019); (Rahmadewi, dan Abundanti, 2018) Return on Equity memiliki pengaruh negatif yang significant terhadap harga saham.

\section{Penutup dan Saran}

\section{Kesimpulan}

Berdasarkan hasil penelitian dan juga pembahasan yang dilakukan oleh peneliti, maka dapat ditarik kesimpulkan dimana tax avoidance dan struktur modal tidak terdapat pengaruh yang signifikan pada perusahaan konstruksi yang terdaftar di BEI pada periode 2018-2019. Dengan adanya return on asset sebagai variabel mediasi maka penghindaran pajak memiliki pengaruh yang signifikan terhadap struktur modal pada perusahaan konstruksi yang terdaftar di BEI periode 2018-2019. Sehingga penghindaran pajak dan struktur modal mempuyai berpengaruh signifikan dengan return on asset sebagai variabel mediasi.

\section{Saran}

Saran yang dapat di sampaikan dalam penelitian ini Untuk manajemen perusahaan agar lebih mempehatikan syarat penghindaran pajak perusahaan dan modal atau pendanaan yang di peroleh dari rusahaan itu sendiri dalam mengatur stuktur modal perusahaan, Peneliti berharap agar pada peneliti berikutnya dapat memperluas atau menambahkan variable independennya supaya memperoleh hasil yang semakin baik pada penelitian selanjutnya, Bagi para penanam saham dan investor agar lebih memperhatikan keuangan perusahaan dalam melakukan pijaman dana dengan menggunakan rasio ROA sebagai pertimbangannya. 


\section{Referensi}

Anbar, A., \& Alper, D. (2011). Bank specific and macroeconomic determinants of commercial bank profitability: Empirical evidence from Turkey. Business and economics research journal, 2(2), 139-152.

Ardiatmi, U. D., \& Sampurno, R. D. (2014). Analisis Pengaruh Current Ratio, Debt to Equity Ratio, Total Asset Turnover, Firm Size dan, Debt Ratio terhadap Profitabilitas (ROE)(Studi Kasus pada Perusahaan Manufaktur Food and Baverages yang Terdaftar di BEI Tahun 20082012) (Doctoral dissertation, Fakultas Ekonomika dan Bisnis).

Azhari, D. F., Rahayu, S. M., \& Zahroh, Z. A. (2016). Pengaruh ROE, DER, TATO, dan PER terhadap Harga Saham Perusahaan Properti dan Real Estate yang Go Publik di Bursa Efek Indonesia. Jurnal Administrasi Bisnis, 32(2), 1-5.

Budiman, J. (2012). Pengaruh Karakter Eksekutif terhadap Penghindaran Pajak (Tax Avoidance) (Doctoral dissertation, [Yogyakarta]: Universitas Gadjah Mada).

Dhani, I. P., \& Utama, A. G. S. (2017). Pengaruh pertumbuhan perusahaan, struktur modal, dan profitabilitas terhadap nilai perusahaan. Jurnal Riset Akuntansi dan Bisnis Airlangga, 2(1), 135-148.

Dyreng, S. D., Hanlon, M., \& Maydew, E. L. (2008). Long-run corporate tax avoidance. The accounting review, 83(1), 61-82.

Hasanah, A. N., \& Ainni, S. N. (2019). Pengaruh Return on Equity (Roe), Earning Per Share (Eps), dan Debt to Equity Ratio (Der) Terhadap Harga Saham JII Yang Terdaftar di Bursa Efek Indonesia (BEI) Tahun 2018. Academica: Journal of Multidisciplinary Studies, 3(1), 139-158.

Hermuningsih, S. (2012). Pengantar Pasar Modal Indonesia. Yogyakarta: UPP STIM YKPN.

Husnan, S. (2001), Dasar-dasar Teori Portofolio dan Analisis Sekuritas. Edisi Ketiga. Yogyakarta: UPP AMP YKPN.

Ilmiani, A., \& Sutrisno, C. R. (2015). Pengaruh Tax Avoidance Terhadap Nilai Perusahan Dengan Transparansi Perusahaan Sebagai Variabel Moderating. Jurnal Ekonomi dan Bisnis, 14(1), 30-39.

Karadeniz, E., Kandir, S. Y., Balcilar, M., \& Onal, Y. B. (2009). Determinants of capital structure: evidence from Turkish lodging companies. International Journal of Contemporary Hospitality Management, 21(5), 594-609.

Kim, C., \& Zhang, L. (2016). Corporate political connections and tax aggressiveness. Contemporary Accounting Research, 33(1), 78-114.

Kristianto, Z., Andini, R., \& Santoso, E. B. (2018). Pengaruh Perencanaan Pajak dan Tax Avoidance Terhadap Nilai Perusahaan dengan Kinerja Keuangan sebagai Variabel Intervening (Studi Empiris Pada Perusahaan Manufaktur Sektor Properti dan Real Estate Yang Terdaftar di BEI Periode (2012-2016). Journal Of Accounting, 4(4).

Kusufiyah, Y. V., \& Anggraini, D. (2018). Dampak tax avoidence terhadap harga saham dengan corporate governance dan ukuran perusahaan sebagai variabel moderating. Jurnal Pundi, 2(1), 1-16.

Lim, Y. (2011). Tax avoidance, cost of debt and shareholder activism: Evidence from Korea. Journal of Banking \& Finance, 35(2), 456-470. 
Manullang, J., Sainan, H., Phillip, P., \& Halim, W. (2019). Pengaruh Rasio Profitabilitas, Solvabilitas, dan Likuiditas terhadap Harga Saham Pada Perusahaan Sektor Pertambangan yang Terdaftar di BEI Periode 2014-2018. Owner: Riset dan Jurnal Akuntansi, 3(2), 129-138.

Midiastuty, P. P., Eddy, S., \& Kristina, K. (2017). Pengaruh Penghindaran Pajak Terhadap Struktur Modal. Simposium Nasional Akuntansi XX Jember. Fakultas Ekonomi Dan Bisnis Universitas Jember.

Mishra, C. S. (2011). Determinants of capital structure-a study of manufacturing sector PSUs in India. In Proceedings of 2011 International Conference on Financial Management and Economics, IPEDR (Vol. 11, pp. 247-52).

Mulatsari, N. T., Wijayanti, A., \& Samrotun, Y. C. (2020). Pengaruh Tax Avoidance, Kepemilikan Institusi dan Kinerja Keuangan terhadap Harga Saham. Ekonomis: Journal of Economics and Business, 4(1), 204-209.

Nababan, L. U. (2019). Penerapan model regresi data panel pada analisis harga saham perusahaan batubara. AKUNTABEL, 16(1), 81-97.

Panggabean, B.M.R. (2018). Pengaruh Ukuran Perusahaan, Leverage, Profitabilitas, Intensitas Aset Tetap, Intensitas Persediaan, Dan Komisaris Independen Terhadap Effective Tax Rate. JOM FEB, 1(1), 1-15.

Prasetyo, W. B. (2019) Perkuat Struktur Modal, Bank Mayapada Tidak Bagi Dividen. beritasatu.com diambil dari https://www.beritasatu.com/whisnu-bagusprasetyo/ekonomi/554665/perkuat struktur-modal-bank-mayapada-tidak-bagidividen

Pratheepan, T., \& Yatiwella, W. B. (2016). The determinants of capital structure: Evidence from selected listed companies in Sri Lanka. International Journal of Economics and Finance, 8(2), 94-106.

Rahmadewi, P. W., \& Abundanti, N. (2018). Pengaruh EPS, PER, CR dan ROE terhadap harga saham di Bursa Efek Indonesia. E-jurnal manajemen universitas udayana, 7(4), 21062182 .

Rudi, R., \& Dwimulyani, S. (2019). Peran Tax Avoidance sebagai Variabel Moderating pada Determinan Struktur Modal. In Prosiding Seminar Nasional Pakar (pp. 2-11).

Sartono, R. (2001). Manajemen Keuangan Teori dan Aplikasi. Edisi 4. Yogyakarta: BPFE.

Seftianne, S., \& Handayani, R. (2011). Faktor-faktor yang mempengaruhi struktur modal pada perusahaan publik sektor manufaktur. Jurnal Bisnis dan Akuntansi, 13(1), 39-56.

Sulistyowati, W. A. (2008). Penentuan Kebijakan Struktur Modal Pada Perusahaan Manufaktur di Bursa Efek Jakarta, Thesis Universitas Diponegoro

Tarihoran, A. (2017). Pengaruh penghindaran pajak dan leverage terhadap nilai perusahaan dengan transparansi perusahaan sebagai variabel moderasi. Jurnal Wira Ekonomi Mikroskil: JWEM, 6(2), 149-164.

Teker, D., Tasseven, O., \& Tukel, A. (2009). Determinants of capital structure for Turkish firms: A panel data analysis. International Research Journal of Finance and Economics, 29, 179187. 
Jurnal Ilmiah Mahasiswa Manajemen, Bisnis dan Akuntansi 2(6) Desember 2020

Widyaningrum, Y. (2015). Pengaruh Profitabilitas, Struktur Aktiva, dan Ukuran Perusahaan Terhadap Struktur Modal Perusahaan. Skripsi. Yogyakarta: Universitas Negeri Yogyakarta. 